\title{
o Comportamento das Receitas de Viagens Internacionais do Brasil: uma explicação macroeconômica
}

\author{
The Behavior of Revenues from International Traveling \\ in Brazil: a macroeconomic explanation
}

Roberto Meurer

\begin{abstract}
RESUMO: No processo de globalização econômica e conseqüente internacionalização dos serviços, o turismo internacional passou a ser um dos principais setores da economia em muitos países por seu volume e renda gerada. Com isso, o comportamento das receitas de viagens internacionais torna-se um tema de relevância. As variáveis macroeconômicas influenciam o comportamento dos viajantes e, por isso, têm de ser levadas em conta para o planejamento do governo e dos agentes privados envolvidos na atividade. Neste trabalho são analisadas as inter-relações entre as variáveis macroeconômicas e as relacionadas com as receitas de viagens internacionais no Brasil. Isso é efetuado por meio de gráficos e dos coeficientes de correlação entre as variáveis. Como resultado da análise para o período entre 1947 e 2003, verificou-se que as variáveis macroeconômicas exercem considerável influência sobre variáveis relacionadas às viagens internacionais, tais como a receita obtida e o número de viajantes. Os resultados foram muito influenciados pelas características do mercado cambial brasileiro, muito centralizado e controlado até 1989, quando passou por um processo de liberalização.
\end{abstract}

PALAVRAS-CHAVE: receitas de viagens internacionais; balanço de pagamentos; Brasil; taxa real de câmbio; número de viajantes.

1. Doutor em Engenharia da Produção; professor do Departamento de Economia da Universidade Federal de Santa Catarina. Contato: Caixa Postal 5062 - CEP 88040-970 - Florianópolis-sC; e-mail: rmeurer@mboxl.ufsc.br. 
ABSTRACT: In the process of economic globalization and services internationalization the international tourism becomes one of the main sectors of the economy. As a result the behavior of revenues from international traveling is very important. Macroeconomic variables have a strong influence on the behavior of the travelers and have to be taken in account in the planning by government and private agents. In this paper the relations between the macroeconomic variables and the ones related with international traveling to Brazil are analyzed. It is verified in the period from 1947 to 2003 that the macroeconomic variables have a strong influence on the Brazilian international traveling revenues and the number of travelers to Brazil. The characteristics of the Brazilian foreign exchange market also influence the results.

KEYWORDS: international traveling revenues; balance of payments; Brazil; real exchange rate; number of travelers.

\section{Introdução}

Neste trabalho procura-se verificar as condicionantes macroeconômicas do comportamento das receitas com viagens internacionais obtidas pelo Brasil desde o início da divulgação dos dados do balanço de pagamentos, em 1947, até 2003. Considera-se que a taxa de câmbio entre o real e o dólar e o comportamento do Produto Interno Bruto - PIB mundial sejam variáveis que podem explicar o comportamento tanto das receitas totais quanto do número de viajantes que visitam o Brasil.

A importância do tema dá-se pelo fato de as variáveis macroeconômicas influenciarem o comportamento dos viajantes e, por isso, ser necessário o conhecimento dessa inter-relação para o planejamento do governo e dos agentes privados envolvidos no setor, especialmente na construção e análise de cenários alternativos. Além disso, a magnitude dos valores envolvidos nas contas de viagens internacionais do balanço de pagamentos torna-as importantes para as contas externas do país, sendo as belezas naturais do Brasil freqüentemente apontadas como solução para o problema de escassez de divisas do país, por meio do turismo receptivo. Uma observação do Gráfico 1 mostra dois fatos importantes. Em primeiro lugar, a conta de viagens internacionais é sistematicamente deficitária, com exceção de 1989 e 2003, tendo o déficit ficado muito elevado nos primeiros anos do Plano Real, em decorrência do aumento das despesas com a sobrevalorização da moeda brasileira. Em segundo lugar, as receitas têm valores absurdamente baixos até 1989, refletindo a estrutura do mercado cambial brasileiro. Essas discrepâncias são percebidas quando analisados os resultados das contas nacio- nais de turismo, em que a participação da exportação de serviços turísticos é consideravelmente mais elevada (Rabahy \& Rejowski, 2001). ${ }^{2}$

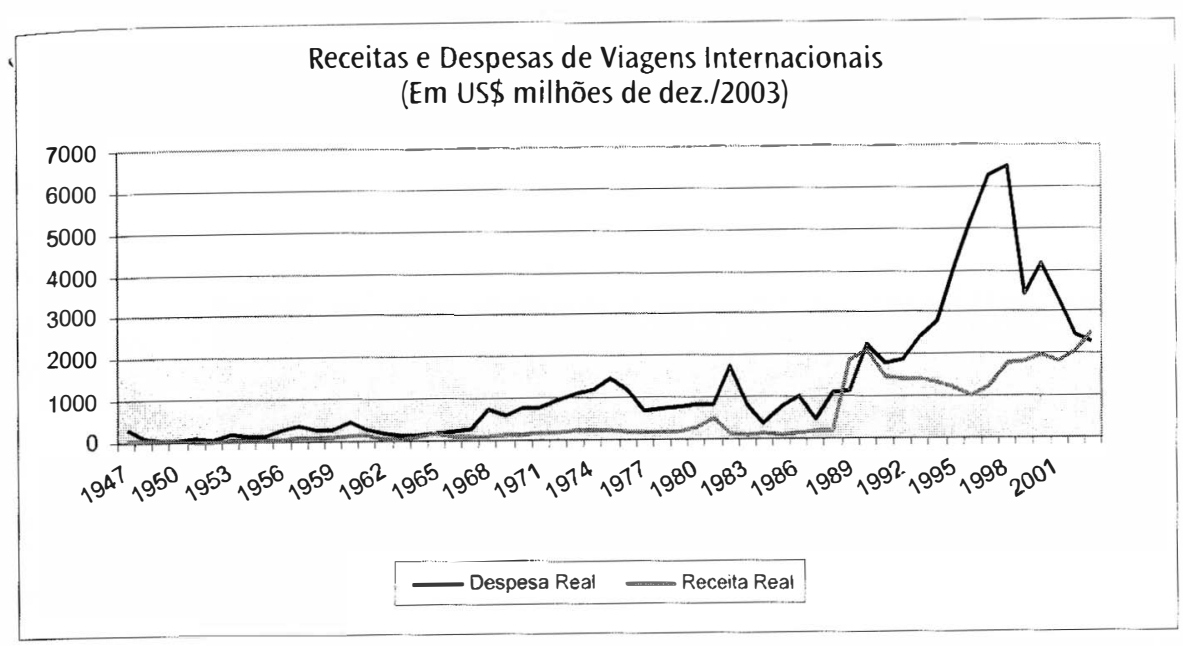

Fonte: Calculado a partir dos dados do Banco Central do Brasil.

Gráfico 1. Receitas e despesas de viagens internacionais - dezembro/2003 (em us\$ milhões)

Para explicar o comportamento das receitas com viagens internacionais obtidas pelo Brasil, será utilizada a análise dos gráficos que mostram a evolução das variáveis ao longo do tempo e os coeficientes de correlação entre as variáveis. Considera-se que a taxa de câmbio é uma medida de custo para o viajante ao país, e que a renda mundial é capaz de explicar parte do comportamento das receitas. $\mathrm{O}$ efeito dessas variáveis pode se dar sobre o valor gasto pelos estrangeiros no país, sobre o número de visitantes ou uma combinação de ambos. Por isso, a análise se dará pelo valor agregado da receita, pelo número de viajantes e pelas receitas por viajante.

O trabalho está estruturado em quatro tópicos, incluindo esta introdução. Na seção 2 explicam-se as relaçōes esperadas entre as variáveis e a forma de obtenção dos dados. Na terceira seção são mostrados os dados e busca-se a explicação para o seu comportamento. São analisadas as variáveis das receitas com viagens internacionais, taxa de câmbio real, PIB mundial e o ágio do câmbio paralelo em relação ao oficial. Por fim, na seção 4 , são apresentadas as principais conclusōes.

2. Os aspectos metodológicos e resultados obtidos para o Sistema de Contas Nacionais de Turismo, a partir da matriz de insumo-produto, são discutidos em Rabahy e Rejowski (2001). 
É óbvio que a explicação macroeconômica não é suficiente para o entendimento do comportamento das receitas com viagens internacionais. Outros aspectos, entre mercadológicos, sociais e culturais, podem levar a uma compreensão mais completa das variáveis analisadas e suas inter-relações. Os aspectos relacionados à oferta, especialmente a montagem e comercialização dos produtos turísticos (Escalona, 1991), não são considerados no trabalho, que, dessa forma, privilegia os aspectos da demanda. Há uma lacuna na literatura sobre o comportamento e a previsão das receitas com viagens internacionais no Brasil, ao contrário do que acontece com outros países do mundo, como evidencia o artigo-resenha de Lim (1997). Exemplos de estudos aplicados a países são Akal (2004), para a Turquia, e Lim e Mcaleer (2001) para a Austrália. A notável exceção para o caso brasileiro são os trabalhos de Rabahy $(1990,1992)$, em que há um tratamento analítico e quantitativo. As publicaçōes da EMBRATUR, como o Relatório Anual do Turismo (emBRATUR, 2003a) e o Estudo da Demanda Turística Internacional (embratur, 2003b), fornecem dados a partir dos quais podem ser aprofundadas as análises.

Apesar de ser senso comum o fato de o Brasil subaproveitar o seu potencial de receitas com o turismo receptivo, esses valores são consideráveis em termos econômicos e importantes para o fechamento das contas internacionais do país. As receitas com viagens internacionais, medidas pelo Banco Central do Brasil no balanço de pagamentos, representaram, em média, $24 \%$ do total das receitas de serviços do Brasil no período 1989 a 2003, e 3\% das exportaçōes de mercadorias. ${ }^{3}$ Como pode ser observado no Gráfico 2, durante a maior parte da década de 1990 , a importância relativa das receitas de viagens internacionais caiu, apresentando alguma recuperação nos anos mais recentes. $\mathrm{O}$ mesmo padrão pode ser verificado para a proporção das receitas em relação à exportação de mercadorias, a principal fonte de divisas para o país. Verifica-se, com esses dados, que, proporcionalmente ao PIB, a magnitude das receitas, no período de 1989 a 2003, é extremamente baixa: apenas $0,27 \%$, em média. Esses valores oscilaram de 0,11\%, em 1996, a 0,5\%, em 2003, refletindo em grande parte as oscilaçōes da taxa de câmbio. Se, por um lado, isso evidencia que o país subutiliza o seu potencial, mostra também que existe um grande espaço para a expansão das receitas.

O turismo internacional é visto como um dos mais importantes setores das economias de muitos países, refletindo a internacionalização dos serviços no contexto da globalização econômica (Fayed \& Fletcher, 2002). Isso explica o aprofundamento das análises dos impactos macroeconômicos do turismo por meio do

3. Os cálculos estão sendo efetuados com os dados a partir de 1989, por causa do já referido problema de pouca representatividade das receitas até 1988, em funçāo da diferença entre o mercado de câmbio paralelo e o oficial/comercial. seu efeito multiplicador sobre toda a atividade econômica (Rabahy \& Rejowski, 2001) e, inversamente, torna necessário o conhecimento dos efeitos do comportamento da economia como um todo sobre o segmento de viagens internacionais.

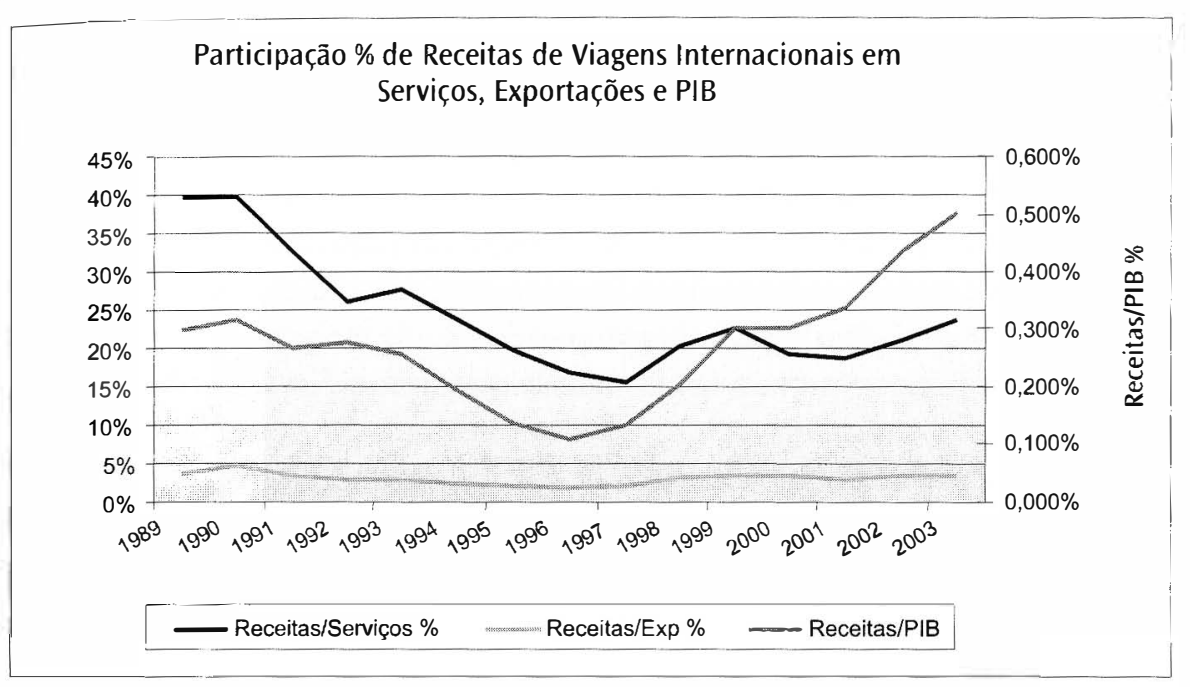

Fonte: Calculado a partir dos dados do Banco Central do Brasil.

Gráfico 2. Participação (\%) de receitas de viagens internacionais em serviços, exportações e PIB

\section{Resultados esperados e dados utilizados}

Os determinantes microeconômicos das viagens internacionais são similares aos de qualquer bem ou serviço (Varisco, 2003), ou seja, renda do demandante, preço do produto e de seu substituto ou complementar. ${ }^{4} \mathrm{O}$ padrão nos estudos sobre turismo considera variáveis explicativas para a demanda turística a renda, 0 custo de transporte, o preço relativo a taxa de câmbio e fatores qualitativos ${ }^{5}$ (Lim, 1997). No caso do preço relativo, está sendo considerado que a taxa real de câmbio seja uma aproximação desse preço: a moeda local desvalorizada significa que

4. Varisco (2003) aprofiunda a discussão sobre os determinantes econômicos e as limitações de sua utilização.

5. Akal (2003) considera importantes os gastos com promoção no exterior como variável explicativa. Rabahy (1990 e 1992) inclui, em sua análise, a ocorrência de ações promocionais no exterio como variável explicativa para a demanda. 
visitar o país está mais barato, porque a mesma quantidade de moeda estrangeira comprará uma maior quantidade de moeda local. Em outras palavras, a taxa de câmbio real expressa os preços externos em termos de moeda local e, por conseqüência, a moeda doméstica mais valorizada significará um preço mais alto para o estrangeiro que visitar o país. Essa abordagem enfatiza a demanda por viagens internacionais, deixando de lado um aspecto fundamental que influencia as decisões de viajar, envolvendo a comercialização dos produtos turísticos por meio de agências de viagem e, especialmente, a montagem e disponibilização dos produtos turísticos, efetuada pelos operadores turísticos (Escalona, 1991). ${ }^{6}$

Supondo que o viajante seja sensível aos preços pagos no destino da viagem, uma valorização da moeda brasileira levaria a uma substituição de destinos, com outros países tomando o lugar do Brasil, que teria ficado mais caro. O inverso aconteceria em períodos em que a moeda brasileira estivesse desvalorizada, porque a viagem ao Brasil se tornaria mais barata, comparativamente a outras alternativas.

A taxa real de câmbio é calculada a partir da fórmula:

$$
\text { CAMR }=\frac{\text { taxa nominal }{ }^{*} \mathrm{CPI}}{\mid \mathrm{GP}-\mathrm{DI}}
$$

sendo que a taxa nominal é a quantidade de moeda brasileira necessária para comprar um dólar americano, CPI é o índice de preços ao consumidor dos Estados Unidos e IGP-DI é o índice de preços do Brasil. Considerando a discussão acima, espera-se que haja uma relação positiva entre desvalorização da moeda brasileira $e$ as receitas de viagens internacionais.

A segunda variável explicativa para as viagens internacionais, além da taxa de câmbio, é a renda no país de origem. O efeito da renda no país de origem sobre as receitas pode se dar de duas formas: por meio do valor gasto pelo viajante ou pelo número de viajantes ao país, ou uma combinação de ambos. Ao possuir maior renda, o viajante terá condições de gastar mais em sua viagem, o que significa que deveria ocorrer aumento da receita total, expressa no aumento da receita por viajante. A segunda possibilidade é decorrente de o aumento da renda possibilitar que pessoas que não podiam viajar passem a fazê-lo, ou seja, haverá aumento do número de estrangeiros visitando o país, o que também aumentará a receita total. ${ }^{7}$

6. A pesquisa com enfoque do lado da oferta na economia do turismo, enfatizado em Escalona (1991), necessita de maior integração com a ênfase na demanda adotada neste trabalho, porque o direcionamento dos fluxos de viajantes é diretamente influenciado pelo comportamento dos produtores/operadores.

7. Akal (2004) encontrou uma forte relação entre número de turistas recebidos e a receita total para a Turquia, utilizando a técnica econométrica de cointegração.
A inclusão do spread do câmbio paralelo em relação ao oficial, na análise, deveu-se ao fato de o mercado cambial brasileiro ser muito controlado até o final da década de 1980, refletindo a restrição de divisas decorrentes dos problemas com o balanço de pagamentos. Com ágio, é mais favorável ao detentor de moeda estrangeira convertê-la no mercado paralelo, em vez do mercado oficial. Com isso, as operações que não passam pelo balanço de pagamentos levam à subestimação das receitas com viagens internacionais, que tenderia a ser tanto maior quanto maior o spread. ${ }^{8}$ Conseqüentemente, espera-se uma relação inversa entre as receitas com viagens internacionais e o spread do câmbio paralelo. O resultado esperado para a correlação entre o spread do câmbio paralelo e o número de viajantes é positivo, porque um maior spread equivale, para o viajante que efetuar o câmbio no mercado paralelo, a uma desvalorização da moeda brasileira.

Existem outros fatores que também afetam as receitas de viagens internacionais, como o gosto dos viajantes, moda em termos de destinos e publicidade positiva ou negativa.' Estes fatores, entretanto, não são tão fáceis de quantificar e, por isso, não são incluídos nesta análise. Os dados das receitas de viagens internacionais não se restringem ao turismo, incluindo todos os motivos para as viagens, como negócios, tratamento de saúde ou esporte. Também estão incluídas, na conta de viagens internacionais, as receitas obtidas por meio de gastos de estrangeiros com cartão de crédito no Brasil, mesmo sem a presença física do detentor do cartão no país. Isso, entretanto, não invalida a análise, porque os fatores explicativos e as relações esperadas entre as variáveis são as mesmas.

Os dados utilizados neste trabalho foram obtidos com diversas fontes e passaram por tratamento para as diferentes análises. Os valores das receitas anuais com viagens internacionais no balanço de pagamentos, obtidos no Banco Central do Brasil (www.bcb.gov.br) em dólares correntes, foram deflacionados pelo índice de preços ao consumidor (CPI) dos Estados Unidos (obtido em http://research. stlouisfed.org/fred2/). A taxa de câmbio real foi calculada aplicando-se a fórmula apresentada anteriormente, utilizando-se a cotação média no ano do dólar dos Estados Unidos, obtida no Banco Central do Brasil, a média no ano do índice de preços ao consumidor dos EUA, e a média no ano do IGPI-DI (Índice Geral de Preços - disponibilidade interna) para os preços no Brasil, coletado no banco de dados do Instituto de Pesquisa Econômica Aplicada - IPEADATA (www.ipeadata. gov.br). Essas taxas de câmbio são as do mercado oficial/comercial/livre, denominação que foi sendo modificada pelas diferentes regulamentações sobre o mercado de câmbio.

8. Os problemas envolvendo a taxa de câmbio são discutidos em Rabahy (1990)

9. Um exemplo de publicidade positiva seria a gerada através dos gastos com promoção. 
Dadas as grandes modificações ocorridas no mercado cambial ao longo do período analisado neste trabalho, quando, em várias ocasiões, o país passou por crises cambiais, também se analisou a inter-relação das variáveis associadas às viagens internacionais, com o spread do mercado paralelo de câmbio em relação ao mercado oficial. O dado da cotação do dólar no mercado paralelo também foi obtido no IPEADATA. $O$ ágio ou spread do câmbio paralelo em relação ao oficial é a diferença porcentual entre as cotações do dólar no mercado paralelo e no oficial. O número de viajantes ao Brasil foi obtido na página da EMBRATUR (www.embratur. gov.br).

\section{Resultados e análise}

Observando-se o Gráfico 3 não existe, para o período analisado, relação aparente entre o comportamento da taxa de câmbio e das receitas de viagens internacionais. Essa conclusão é influenciada pelos valores irrisórios das receitas observadas até 1988. A análise dos coeficientes de correlação, mostrados nas tabelas 1 e 2, confirma essa conclusão, dado o baixo valor do coeficiente, de apenas 0,1 . O coeficiente de correlação é um número que varia entre - 1 e 1 e indica quanto afastamentos da média em uma variável estão associados a afastamentos da média em outra. Quanto mais próximo da unidade estiver o coeficiente de correlação, mais as variáveis comportam-se de maneira similar, enquanto valores

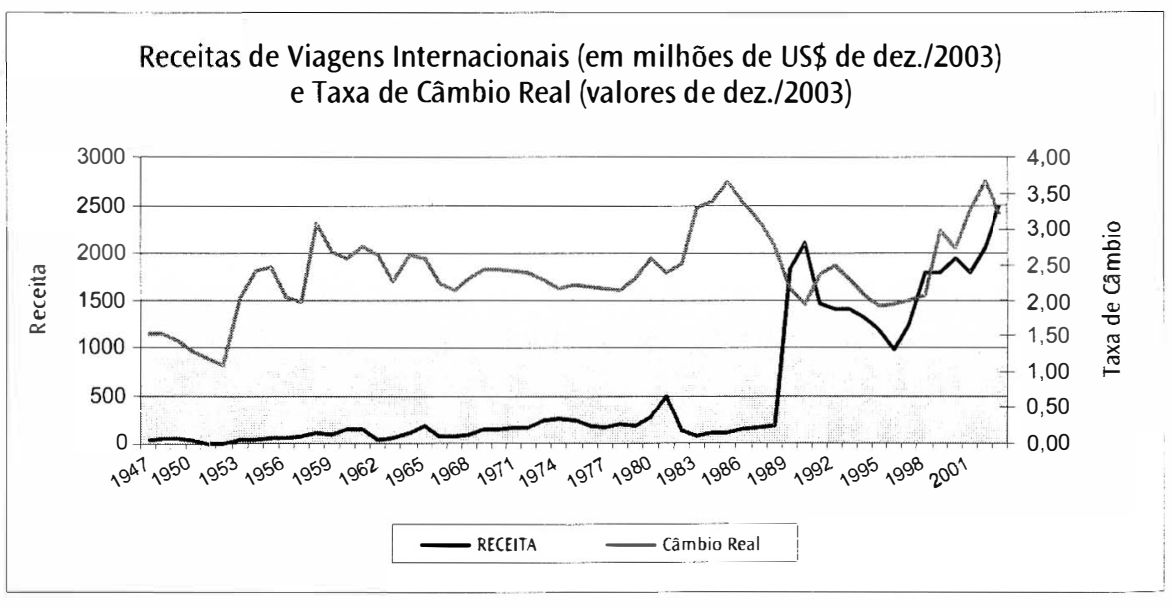

Fonte: Calculado a partir dos dados do Banco Central do Brasil e Federal Reserve.

Gráfico 3. Receitas de viagens internacionais (em milhões de US\$ - dezembro/ 2003) e taxa de câmbio real (valores de dezembro/2003) próximos de -1 indicam comportamento inverso. Se os valores do coeficiente forem próximos de zero, o comportamento das duas variáveis não tem relação. Claramente, esses resultados da receita, próxima de zero até 1988, são irreais e đecorrem das características do mercado cambial anteriormente à sua liberalização, a partir do final da década de 1980. Para contornar esse problema, que geraria resultados pouco confiáveis, também foram calculados os coeficientes de correlação apenas para o período posterior a 1989.

Para os dados a partir de 1989, parece haver a relação esperada de que um aumento da taxa de câmbio real (desvalorização da moeda brasileira) é acompanhado de um aumento das receitas e vice-versa, como mostra o coeficiente positivo de 0,54 (os coeficientes de correlação são apresentados nas tabelas 1 e 2). Uma análise do gráfico para o período mais recente também indica isso, quando se observa que as menores receitas foram obtidas nos anos de início do Plano Real. Entretanto, essa explicação não é completa, uma vez que, em 1997 e 1998, o câmbio continuou desfavorável ao turismo receptivo, mas as receitas aumentaram.

O pouco realismo dos dados de receitas até 1988, referido anteriormente, pode ser ilustrado pela observação da receita por viajante, mostrada no Gráfico 4. Os valores das receitas por viajante apresentam-se absurdamente baixos. Os valores observados entre 1983 e 1987, os mais baixos, situaram-se entre 50 e cem dólares, o que significaria que o viajante estrangeiro ao Brasil, considerando uma estada de 12 dias, gastou menos de dez dólares por dia. É interessante observar

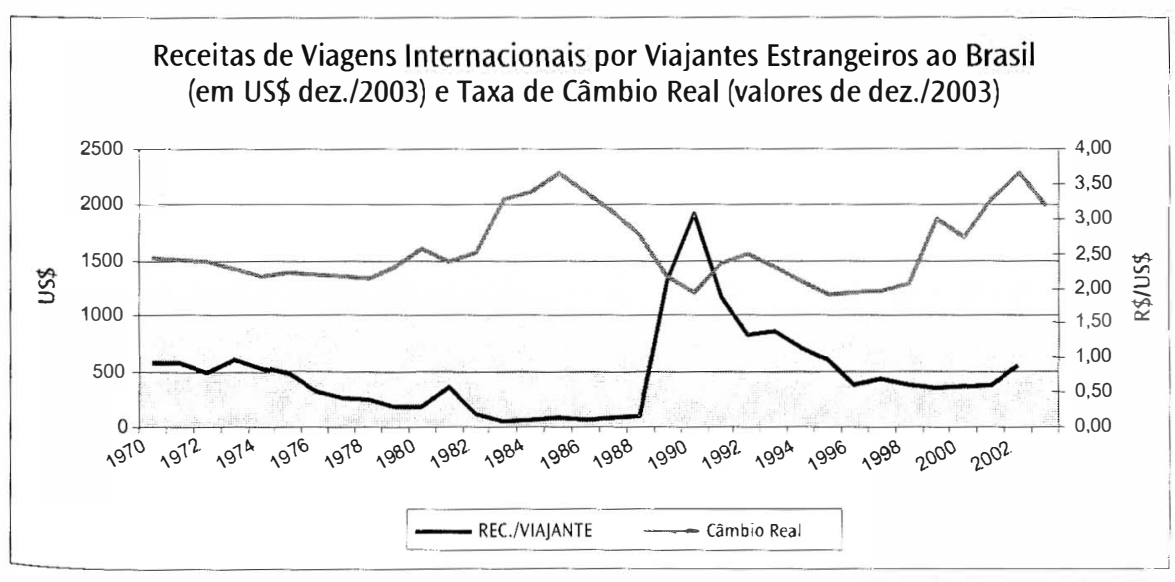

Fonte: Calculado a partir dos dados do Banco Central do Brasil e Federal Reserve.

Gráfico 4. Receitas de viagens internacionais por viajante estrangeiro ao Brasil (em US\$-dezembro/2003) e taxa de câmbio real (valores de dezembro/ 2003) 
que, nos anos mais recentes, a receita total obtida por viajante retornou para patamares próximos aos observados no início da década de 1970.

A correlação entre a receita por viajante e a taxa real de câmbio é de $-0,46$ para o período 1970-2002, e de -0,33 para o período 1989-2002. O coeficiente negativo indica que as duas variáveis têm comportamentos inversos: uma desvalorização da taxa de câmbio leva a uma redução dos gastos por viajante. Isso pode estar indicando que o viajante estrangeiro faz as suas despesas em moeda doméstica e, com a taxa de câmbio desvalorizada, necessita de menos moeda estrangeira para o mesmogasto dentro do país. Em caso de valorização da moeda brasileira, é necessário maior quantidade de moeda estrangeira para o mesmo consumo no país, o que leva ao aumento da receita por viajante que vem ao país. Em outras palavras, os gastos efetuados no Brasil por viajantes estrangeiros parecem não se modificar, enquanto os preços internos medidos em moeda estrangeira se modificam.

O Gráfico 5 mostra o comportamento do número de viajantes ao país e a taxa de câmbio. Seria de esperar que houvesse uma relação positiva entre essas variáveis, porque a moeda nacional depreciada significa que os gastos dentro do país se tornam mais baratos em relação ao restante do mundo. Aparentemente, existe uma relação direta entre o número de estrangeiros viajando ao Brasil e a taxa de câmbio real até 1994. A partir daí, a taxa de câmbio passa a ficar estável, mas o número de visitantes continua a aumentar. Em 2001 e 2002, apesar da desvalorização real da moeda brasileira, o número de visitantes caiu. Esse com-

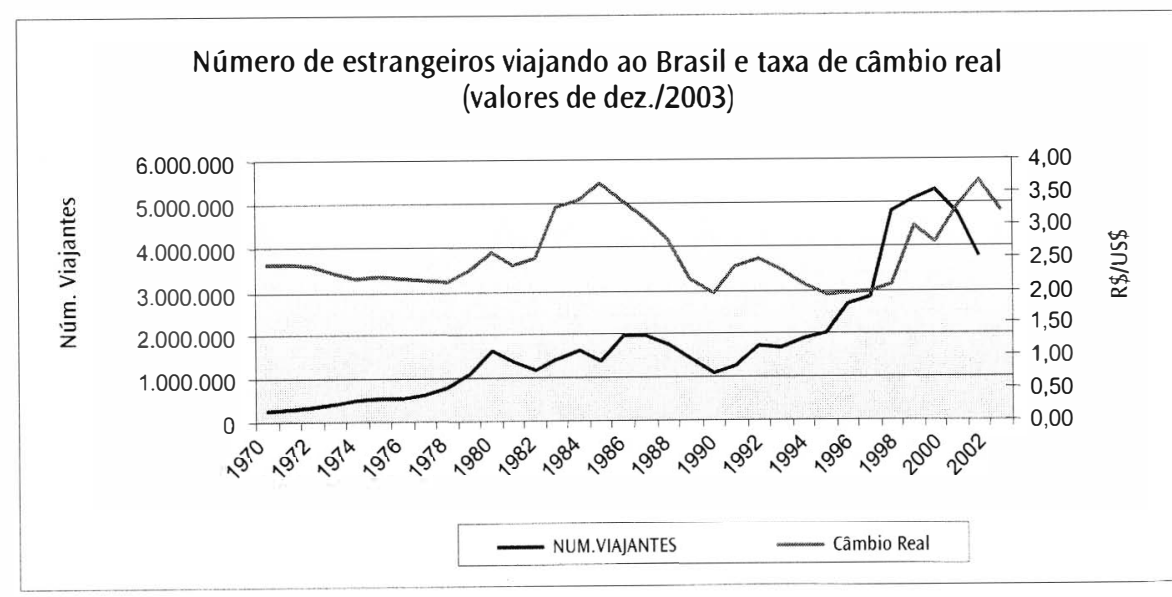

Fonte: Calculado a partir dos dados do Banco Central do Brasil e Federal Reserve (câmbio real), e da EMBRATUR (número de viajantes).

Gráfico 5. Número de estrangeiros viajando ao Brasil e taxa de câmbio real (valores de dezembro/2003) portamento, em 2001 e 2002, pode ter sido influenciado por questōes econômicas específicas dos países emissores de viajantes ao Brasil, como PIB e taxa de câmbio, conforme ocorreu com a Argentina. Isso seria compatível com o resultado, obtido por Rabahy (1990 e 1992), de que os fluxos de viajantes ao Brasil, oriundos de países próximos, são mais sensíveis a mudanças conjunturais que os fluxos inter-regionais. A queda do número de viajantes também foi influenciada pela redução generalizada das viagens internacionais a partir do atentado ocorrido em Nova York. Verificando-se o coeficiente de correlação, este é de 0,3 para o período integral, e de 0,57 para o período mais recente (1989-2002). Portanto, os resultados estão de acordo com o esperado. Rabahy $(1990,1992)$ encontrou forte evidência econométrica da importância da taxa de câmbio para explicar o fluxo de argentinos ao Brasil, mostrando que uma valorização real da moeda argentina em relação à brasileira, leva a uma redução do número de chegadas ao Brasil. Esse resultado com o número de viajantes é interessante porque não é tão influenciado pelas características do mercado cambial quanto a receita total e aquela por viajante ingressado no país. Trabalhos anteriores, como Rabahy (1990, 1992), por isso, tiveram de restringir-se ao número de viajantes.

A relação positiva entre o número de viajantes ao Brasil e o comportamento do PIB mundial, visível no Gráfico 6, é clara. Nota-se que há maiores oscilaçōes no número de viajantes que no PIB, o que evidencia a necessidade de analisarem-se outras variáveis para explicar o número de viajantes ao Brasil. Como esperado, a

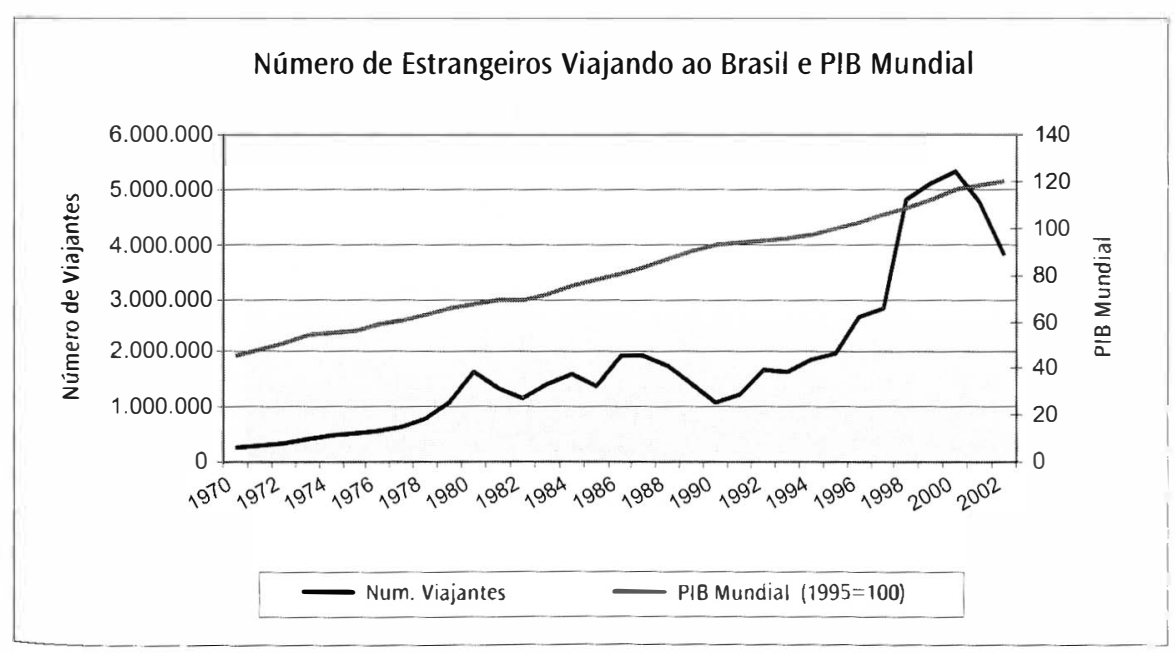

Fonte: EMBRATUR (número de viajantes). Calculado a partir de dados do IPEADATA (PIB mundial).

Gráfico 6. Número de estrangeiros viajando ao Brasil e PIB mundial 
correlação entre as duas variáveis é muito forte, próxima da unidade 0,86 para o período 1970-2002, e 0,9 para o período 1989-2002. Essa forte inter-relação já havia sido destacada por Rabahy $(1990,1992)$.

O comportamento das receitas totais com viagens internacionais e o spread do câmbio paralelo em relação ao oficial é claramente inverso, como pode ser visto no Gráfico 7. O processo de redução do spread do câmbio paralelo em relação ao oficial, decorrente de maior liberalização do mercado cambial a partir de 1989, foi acompanhado do aumento das receitas de viagens internacionais. Isso é explicado pelo fato de, com a redução do spread, não haver mais tanto benefício com a venda da moeda estrangeira fora do mercado legal. Uma possibilidade que explica a ocorrência do pico das receitas de viagens internacionais do início da década de 1990 é a venda de dólares por brasileiros sem identificação, o que classificaria tais vendas como sendo de estrangeiros. Isso significa que uma parcela das transações efetuadas especialmente por pessoas físicas passou a ocorrer no mercado de câmbio turismo, podendo ser de operações que funcionavam como aplicação financeira, uma vez que as elevadas taxas de inflação impediam a manutenção da função de reserva de valor para a moeda brasileira. Anteriormente, essas transações eram efetuadas de forma sistemática no mercado paralelo, mas com a redução do spread, podem ter se deslocado para o mercado legal. Como esse movimento de redução do spread e aumento das receitas foi único, não é detectado pelos coeficientes de correlação, que é negativo, como esperado, mas baixo para todo o período 1970-2002, e positivo e baixo para o período posterior a 1989.

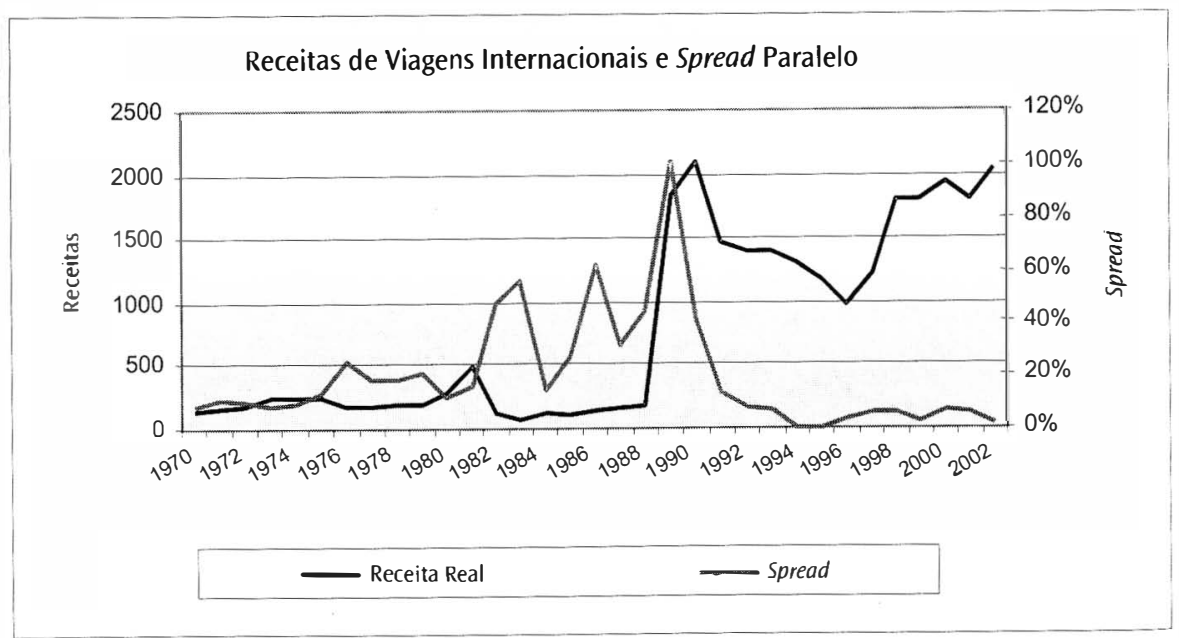

Fonte: Calculado a partir de dados do Banco Central do Brasil e IPEADATA.

Gráfico 7. Receitas de viagens internacionais e spread paralelo
O número de viajantes poderia ser influenciado pelo spread porque um spread maior significa maior quantidade de moeda brasileira para uma mesma quantidade de moeda estrangeira, ou seja, uma redução de preços para o visitante. Neste caso, o comportamento deveria ser no mesmo sentido: maiores spreads, maior número de viajantes. Visualmente, não se consegue detectar esse padrão no Gráfico 8. O coeficiente de correlação entre as variáveis é negativo, o que pode ser explicado pela redução do spread a partir de 1989, ao mesmo tempo que aumenta o número de viajantes.

Algumas conclusões podem ser tiradas dos coeficientes de correlação apresentados nas tabelas 1 e 2 . Existe uma relação positiva muito forte e esperada entre o número de viajantes e a receita obtida. A relação entre o comportamento do número de viajantes e o comportamento do PIB mundial também é forte e de acordo com o esperado, uma vez que maior rendimento das famílias no mundo fará com que haja maior possibilidade de elas viajarem ao Brasil. Esses dois resultados explicam, por conseqüência, a forte relação positiva entre PIB mundial e a receita real.

Dos resultados das correlações envolvendo a receita total e a receita por viajante, é mais prudente analisar os dados do período após a liberalização do mercado cambial, a partir de quando não havia mais tanta vantagem em vender a moeda estrangeira no mercado paralelo em relação a agentes credenciados pelo Banco Central do Brasil. Um aspecto importante é a correlação de 0,54 entre a receita total com viagens internacionais e a taxa de câmbio real. Essa correlação

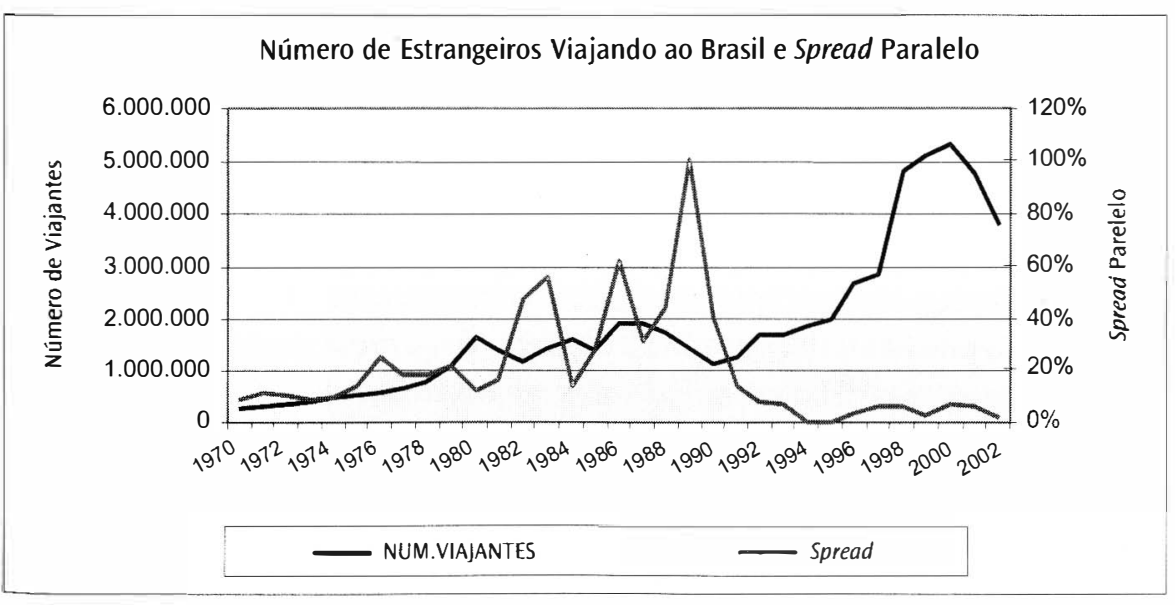

Fonte: Dados calculados a partir de dados da EMBRATUR e Banco Central do Brasil.

Gráfico 8. Número de estrangeiros viajando ao Brasil e spread paralelo 
não tão forte mostra uma certa insensibilidade das receitas à variável de custo da viagem, expressa na taxa de câmbio. Como as receitas são medidas em dólar, isso significa que o fato de os gastos no Brasil serem mais acessíveis não tem como conseqüência um grande aumento dos gastos quando medido em moeda estrangeira. Isso provavelmente significa que os estrangeiros continuam gastando a mes-

Tabela 1. Coeficientes de correlação - 1970 a 2002

\begin{tabular}{lcccccc}
\hline & $\begin{array}{c}\text { Número } \\
\text { de viajantes }\end{array}$ & $\begin{array}{c}\text { Câmbio } \\
\text { real }\end{array}$ & $\begin{array}{c}\text { Receita/ } \\
\text { viajante }\end{array}$ & $\begin{array}{c}\text { PIB } \\
\text { mundo }\end{array}$ & $\begin{array}{c}\text { Receita } \\
\text { total }\end{array}$ & Spreed \\
\hline Número de viajantes & 1 & & & & & \\
Câmbio real & 0,300 & 1 & & & & \\
Receita/viajante & $-0,122$ & $-0,459$ & 1 & & 1 & \\
PIB mundo & 0,862 & 0,179 & 0,187 & 1 & 1 \\
Receita total & 0,692 & $-0,105$ & 0,608 & 0,843 & 1 & \\
Spreed & $-0,241$ & 0,155 & 0,097 & $-0,134$ & $-0,144$ & 1 \\
\hline
\end{tabular}

Fonte: Calculado a partir de dados do Banco Central do Brasil, IPEADATA, Federal Reserve e EMBRATUR.

Tabela 2. Coeficientes de correlação - 1989 a 2002

\begin{tabular}{lcccccc}
\hline & $\begin{array}{c}\text { Número } \\
\text { de viajantes }\end{array}$ & $\begin{array}{c}\text { Câmbio } \\
\text { real }\end{array}$ & $\begin{array}{c}\text { Receita/ } \\
\text { viajante }\end{array}$ & $\begin{array}{c}\text { PIB } \\
\text { mundo }\end{array}$ & $\begin{array}{c}\text { Receita } \\
\text { total }\end{array}$ & Spreed \\
\hline Número de viajantes & 1 & & & & & \\
Câmbio real & 0,571 & 1 & & & & \\
Receita/viajante & $-0,744$ & $-0,333$ & 1 & & 1 & \\
PIB mundo & 0,904 & 0,727 & $-0,726$ & 1 & 1 \\
Receita total & 0,375 & 0,544 & 0,287 & 0,354 & 1 & \\
Spreed & $-0,390$ & $-0,213$ & 0,643 & $-0,486$ & 0,356 & 1 \\
\hline
\end{tabular}

Fonte: Calculado a partir de dados do Banco Central do Brasil, IPEADATA, Federal Reserve e EMBRATUR. ma coisa dentro do Brasil sem aumentar os gastos pelo fato de terem sido beneficiados com uma redução de custos em termos de moeda estrangeira. Para comprovar essa indicação podemos ver que a correlação entre a taxa de câmbio real e o número de viajantes ao Brasil é praticamente a mesma, 0,57. Apesar de essa 'análise necessitar de um detalhamento quantitativo, pode-se perceber que há necessidade de trabalhar o aspecto de custo da viagem ao Brasil, uma vez que, mesmo em períodos de moeda brasileira valorizada, ou seja, quando era mais caro para os estrangeiros virem ao Brasil, eles não deixaram de fazê-lo.

\section{Conclusão}

Neste trabalho foi possível verificar que as variáveis macroeconômicas exercem considerável influência sobre as variáveis relacionadas às viagens internacionais, como a receita obtida e o número de viajantes. Os resultados foram muito influenciados pelas características do mercado cambial brasileiro, que era muito centralizado até 1989 , quando passou a ser mais livre, tornando viável a venda da moeda estrangeira gasta pelos viajantes em mercados legais, o que anteriormente ocorria no mercado paralelo e, por conseqüência, não era detectado nas estatísticas do balanço de pagamentos.

Um aprofundamento do presente trabalho poderia ser obtido ao se detectarem os efeitos das variáveis macroeconômicas desagregadas por país, na linha apontada por Rabahy $(1990,1992)$. Com isso, as variáveis dos países com maior expressão como emissores de viajantes para o Brasil poderiam ter um tratamento pormenorizado, e as variáveis que, no agregado, não se mostraram muito eficazes para a explicação, poderiam ter mais sucesso, evitando possíveis compensações entre países. Com isso, o efeito da taxa de câmbio específica do país de origem e o comportamento da renda per capita de seus habitantes poderiam ter uma quantificação consistente.

Nesta linha, cabe uma análise econométrica multivariada que possa quantificar as relações entre as variáveis, visando a estimar as elasticidades das receitas a variáveis como PIB do país emissor, taxa de câmbio em relação ao país emissor e despesas com promoção no exterior, de acordo com a metodologia sugerida por Varisco (2003) e implementada por Rabahy $(1990,1992)$. Esses resultados seriam importantes para o planejamento macroeconômico do país, sobretudo quanto às projeções do balanço de pagamentos e necessidades de obtenção de financiamento externo ou alocação de excedentes. No nível microeconômico, esses resultados seriam úteis para os agentes do setor efetuarem análises de cenários alternativos de comportamento da economia externa e seus reflexos sobre gastos e número de 
viajantes. As estimativas poderiam ser efetuadas com dados em diferentes freqüências, visando a capturar aspectos específicos do comportamento das receitas.

Os resultados aqui apresentados mostram que o total das receitas obtidas pelo Brasil com viagens internacionais é sensível à taxa de câmbio e ao PIB mundial. O mesmo acontece com o número de viajantes. Tais resultados estão de acordo com o esperado teoricamente. Entretanto, a receita por viajante tem uma relação inversa com a taxa de câmbio real, indicando que os gastos efetuados no país não são influenciados pelo seu preço medido em moeda estrangeira.

\section{Referências bibliográficas}

AKAL, Mustafá. 2004. Forecasting Turkey's tourism revenues by ARMAX model. Tourism Management, v. 25, p. 565-580.

EMBRATUR. 2003a. Anuário Estatístico Embratur, vol. 30. Brasília.

EMBRATUR. 2003b. Estudo da Demanda Turística Internacional 2002. Brasília.

ESCALONA, Francisco Muñoz de. 1991. Crítica de la economía turística: enfoque de oferta versus enfoque de demanda. Tese (Doutorado) - Universidad Complutense de Madrid. Disponível em: <http://www.eumed.net/tesis>.

FAYED, H. \& FLETCHER, J. 2002. Globalization of economic activity: issues for tourism. Tourism Economics, v. 8, n. 2, p.207-230.

LIM, Christine. 1997. Review of international tourism demand models. Annals of Tourism Research, v. 24, n. 4, p.835-849.

LIM, Christine \& MCALEER, Michael. 2001. Forecasting tourist arrivals. Annals of Tourism Research, v. 28, n. 4, p. 965-977.

RABAHY, Wilson A. \& REJOWSKI, Mirian. 2001. Experiência brasileira em contas nacionais do Turismo, Turismo em Análise, v. 12, n. 2, nov., p.32-42.

RABAHY, Wilson A. 1992. Modelo de predicción: un proyecto experimental en Brasil. Estudios $y$ Perspectivas en Turismo, v. 1, n. 3, p. 198-215.

1990. Fundamentos econômicos e quantitativos no planejamento turístico. Turismo em Análise, v. 1, n. 1, maio, p. 35-54.

VARISCO, Cristina. 2003. Consideraciones metodológicas para el estudio de las variables económicas que inciden en la demanda turística, Turismo em Análise, v. 14, n. 2, nov., p.53-66.

Recebido em: 25/10/2004 (1ª versāo) e 31/01/2005 (2ª versāo).

Aprovado em: 17/02/2005. 